\title{
Characterization of Ethylene-propylene Composites Filled with Perlite and Vermiculite Minerals: Mechanical, Barrier, and Flammability Properties
}

\author{
Bolesław Szadkowski ${ }^{1, *(1)}$, Anna Marzec ${ }^{1, *(\mathbb{C})}$, Przemysław Rybiński ${ }^{2}$ (), Witold Żukowski ${ }^{3}$ (D) \\ and Marian Zaborski ${ }^{1}$ \\ 1 Institute of Polymer and Dye Technology, Faculty of Chemistry, Lodz University of Technology, \\ Stefanowskiego 12/16, 90-924 Lodz, Poland; marian.zaborski@p.lodz.pl \\ 2 Institute of Chemistry, The Jan Kochanowski University, Żeromskiego 5, 25-369 Kielce, Poland; \\ przemyslaw.rybinski@ujk.edu.pl \\ 3 Department of Chemical Engineering and Technology, Cracow University of Technology, 31-155 Kraków, \\ Poland; pczukows@pk.edu.pl \\ * Correspondence: boleslaw.szadkowski@edu.p.lodz.pl (B.S.); anna.marzec@p.lodz.pl or \\ marzec.anna@hotmail.com (A.M.)
}

Received: 20 November 2019; Accepted: 21 January 2020; Published: 27 January 2020

\begin{abstract}
Perlite and vermiculite are naturally occurring minerals, commonly used by industry to obtain highly thermoisolative and/or non-flammable materials. However, there has been little research into the preparation and application of rubber compounds containing these inexpensive mineral fillers. Here, we show the benefits of perlite and vermiculite minerals as fillers for ethylene-propylene rubber (EPM) composites. To obtain more uniform dispersion and improved compatibility between the minerals and the elastomer matrix, 1-allyl-3-methylimidazolium bis(trifluoromethylsulfonyl)imide (AMIMTFSI) and 1-butyl-3-methylimidazolium bis(trifluoromethylsulfonyl)imide (BMIMTFSI) imidazolium ionic liquids (ILs) were added. The mineral fillers were found to be attractive semi-reinforcing fillers, which also act as flame retardants in the elastomer composites. Furthermore, a higher content of vermiculite mineral significantly reduced the air permeability of the composites. The incorporation of ionic liquids into the EPM-filled systems had a considerable effect on the torque increment, crosslink density, and more importantly the flammability of the studied compounds. The application of 2.5 parts per hundred parts of rubber (phr) BMIMTFSI, in particular, reduced the flammability of the EPM composite, as the maximum heat release rate $\left(H R R_{\max }\right)$ decreased from $189.7 \mathrm{~kW} / \mathrm{m}^{2}$ to $170.2 \mathrm{~kW} / \mathrm{m}^{2}$.
\end{abstract}

Keywords: ethylene-propylene rubber; perlite; vermiculite; ionic liquids; composite properties

\section{Introduction}

Elastomer materials have found a wide range of applications in many sectors, such as the aircraft, marine, and construction industries, due to their properties, such as light weight, good toughness, and thermal resistance [1]. Superior qualities such as gas and solvent barrier properties, mechanical strength, and high fire retardancy are additional important characteristics. The fire retardancy of polymer materials can be improved by the addition of flame retardant additives, or by processing following the polymerization process [2]. Recently, carbon nanotubes (CNTs) [3-5], layered double hydroxides [6,7], montmorillonite (MMT) [8-10], and halloysite [11] have been proposed as halogen-free fire-retardant materials. Other compounds used as eco-friendly fire-retardant compounds in polymers include chitosan phosphate, starch-based materials, and melamine [12,13]. Metal hydroxides and 
phosphorous compounds are also interesting halogen-free fire-retardant compounds for polymers, due to their low toxicity and low cost [14].

Vermiculite clay $\left((\mathrm{Mg}, \mathrm{Fe}, \mathrm{Al})_{3}(\mathrm{Al}, \mathrm{Si})_{4} \mathrm{O}_{10}(\mathrm{OH})_{2} \cdot 4 \mathrm{H}_{2} \mathrm{O}\right)$, a mica-type silicate, is known for its flame-retardant properties $[15,16]$. An interesting property of vermiculite (VMT) is its exfoliation at elevated temperature, due to the loss of water in the interlayers [17]. Its many advantages include high resistance to chemicals and heat, cation interchangeability, temperature retention, and water adsorption capacity $[18,19]$. Vermiculite has also been used as a reinforcement for the preparation of polymer nanocomposites. Takahashi et al. [20] used VMT to enhance the gas barrier properties of butyl rubber coatings. Due to its heat-resistant characteristics, VMT has been applied in flame-resistant polypropylene composites [21,22]. When incorporated into polyurethanes, VMT simultaneously improves its tensile and flexural strength [23].

Another interesting inorganic compound is perlite (PT). Formed by the cooling of volcanic eruptions, it is mainly composed of $\mathrm{SiO}_{2}, \mathrm{Al}_{2} \mathrm{O}_{3}, \mathrm{~K}_{2} \mathrm{O}, \mathrm{Na}_{2} \mathrm{O}$, and water. However, depending on its origin PT may also contain $\mathrm{TiO}_{2}, \mathrm{CaO}$, and $\mathrm{MgO}$ [24]. As with VMT, when subjected to thermal treatment PT particles expand up to 20 times in volume, due to the water vaporization [25]. Applications of polyethylene prepared with the addition of PT have been reported previously [26,27]. Recently, Karaca et al. [28] showed that PT enhanced the thermal stability and sound absorption coefficients of polyesters. However, there have until now been no reports in the literature regarding the application of VMT and PT fillers in ethylene-propylene rubber (EPM) elastomer to improve its fire retardancy.

In this work, natural PT and VMT materials were added for the first time to EPM rubber at different concentrations and studied for their effects on its mechanical and flame-resistant properties. Two ionic liquids (ILs), 1-allyl-3-methylimidazolium bis(trifluoromethylsulfonyl)imide (AMIMTFSI) and 1-butyl-3-methylimidazolium bis(trifluoromethylsulfonyl)imide (BIMTFSI), were used as dispersing agents. Their impact on the flammability of the EPM composites was also studied. The ionic salts were selected based on our previous studies, in which they had been used to improve silica and hydrotalcite dispersion in acrylonitrile-butadiene (NBR) and carboxylated acrylonitrile-butadiene (XNBR) rubber, respectively [29-31].

\section{Materials and Methods}

\subsection{Raw Materials}

Ethylene-propylene rubber with the commercial name Dutral CO-54, provided by Versalis S.p.A. (Milan, Italy), was applied as an elastomer matrix. The crosslinking system consisted of dicumyl peroxide (DCP) as a curing agent and 1,3,5-triallyl-1,3,5-triazine-2,4,6 $(1 \mathrm{H}, 3 \mathrm{H}, 5 \mathrm{H})$-trione (TTT) as a crosslinking co-agent, both purchased from Sigma-Aldrich (Schnelldorf, Germany). 1-Allyl-3methylimidazolium bis(trifluoromethylsulfonyl)imide (AMIMTFSI) and 1-butyl-3- methylimidazolium bis(trifluoromethylsulfonyl)imide (BMIMTFSI) were also purchased from Sigma-Aldrich. Two different mineral fillers were used, perlite (PT) and vermiculite (VMT) from Torimex-chemicals Ltd. Sp. z o.o. (Lodz, Poland).

\subsection{Preparation and Characterization Techniques}

Elastomer blends were prepared on a laboratory mixing mill with a roll length of $330 \mathrm{~mm}$ and a diameter of $140 \mathrm{~mm}$. Each compound was mixed with friction of 1.1, at a temperature of $40{ }^{\circ} \mathrm{C}$, for approximately $15 \mathrm{~min}$. The EPM was first masticated for $3 \mathrm{~min}$ on the mill. The other the ingredients (filler, dispersing agents and curing agent) were then successively added to the EPM matrix. Prior the composite preparation, mineral fillers were subjected to the grinding process in classic line planetary ball mill (Fritsch, Idar-Oberstein, Germany). The recipe for the EPM rubber composites is presented in Table 1. 
Table 1. Composition of EPM-filled mixtures (in phr-parts per hundred parts of rubber).

\begin{tabular}{cccccccc}
\hline Compound & Neat EPM & DCP & TTT & Perlite & Vermiculite & AMIMTFSI & BMIMTFSI \\
\hline EPM & 100 & 1 & 0.25 & 0 & 0 & 0 & 0 \\
EPM/5PT & 100 & 1 & 0.25 & 5 & 0 & 0 & 0 \\
EPM/10PT & 100 & 1 & 0.25 & 10 & 0 & 0 & 0 \\
EPM/20PT & 100 & 1 & 0.25 & 20 & 0 & 0 & 0 \\
EPM/20PT/AMIMTFSI & 100 & 1 & 0.25 & 20 & 0 & 2.5 & 0 \\
EPM/20PT/BMIMTFSI & 100 & 1 & 0.25 & 20 & 0 & 0 & 2.5 \\
EPM/5VMT & 100 & 1 & 0.25 & 0 & 5 & 0 & 0 \\
EPM/10VMT & 100 & 1 & 0.25 & 0 & 10 & 0 & 0 \\
EPM/20VMT & 100 & 1 & 0.25 & 0 & 20 & 0 & 0 \\
EPM/20VMT/AMIMTFSI & 100 & 1 & 0.25 & 0 & 20 & 2.5 & 0 \\
EPM/20VMT/BMIMTFSI & 100 & 1 & 0.25 & 0 & 20 & 0 & 2.5 \\
\hline
\end{tabular}

After $24 \mathrm{~h}$, the elastomer mixtures were subjected to rheometric measurements using a moving die rheometer model (Alpha Technologies, New York, NY, USA), according to the ISO 6502 standard. The curing process was performed on an electrically heated hydraulic press at $160{ }^{\circ} \mathrm{C}$ with $15 \mathrm{MPa}$ of pressure for a curing time consistent with the vulcanization parameters. As a result, a series of cured ethylene-propylene rubber composites loaded with different quantities of perlite and vermiculite minerals were obtained (Figure 1).

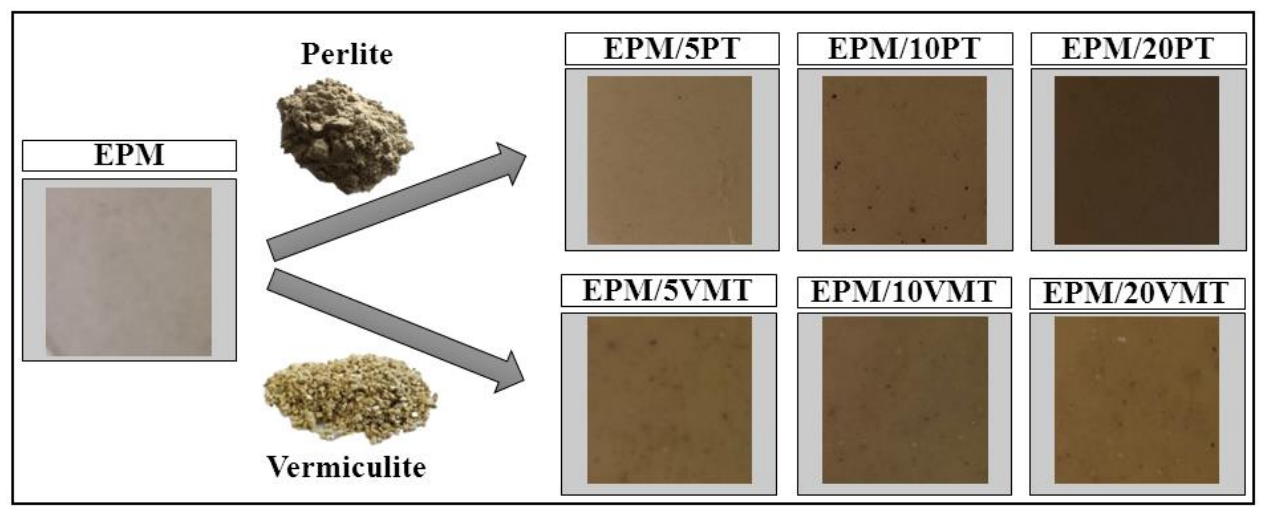

Figure 1. Digital photographs of EPM vulcanizates filled with different contents of perlite and vermiculite.

The crosslink density of the EPM vulcanizates was determined based on the equilibrium swelling method, performed in toluene solvent at room temperature. The crosslink density values were calculated from the Flory-Rehner equation [32]:

$$
v_{\mathrm{e}}=-\left[\ln \left(1-\mathrm{V}_{\mathrm{r}}\right)+\mathrm{V}_{\mathrm{r}}+\mu \cdot \mathrm{Vr}^{2}\right] /\left[\mathrm{V}_{0}\left(\mathrm{~V}_{\mathrm{r}}^{(1 / 3)}-\left(\mathrm{V}_{\mathrm{r}} / 2\right)\right]\right.
$$

where $v_{\mathrm{e}}$ is the crosslink density, $\mathrm{V}_{\mathrm{r}}$ is the volume fraction of the elastomer in swollen gel, $\mathrm{V}_{0}$ is the molar volume of the solvent $\left[\mathrm{mol} / \mathrm{cm}^{3}\right]$ and $\mu$ is the Huggins parameter, determined based on the equation:

$$
\mu=\mu_{0}+\beta \cdot V_{r}
$$

where the polymer-solvent interaction parameters for the studied system are $\mu_{0}=0.501$ and $\beta=0.273$.

The mechanical properties were investigated using a universal strength machine (Zwick, Ulm, Germany) equipped with an extensometer. A tensile test was carried out for five dumbbell-shaped specimens of each composite at a crosshead speed of $500 \mathrm{~mm} / \mathrm{min}$, according to the ISO37 standard. The tear resistance of the composites was measured in accordance with the ISO 34-1 standard for three trouser-shaped samples of each composite at a test speed of $50 \mathrm{~mm} / \mathrm{min}$. The air permeability of the 
EPM composites was determined using the manometric method. The gas transmission rate (GTR) was calculated from the equation [33].

$$
\mathrm{GTR}=\frac{V_{C}}{R \cdot T \cdot P_{U} \cdot A} \cdot \frac{d p}{d t}
$$

where $V_{C}$ is the volume of the low-pressure chamber $(\mathrm{L}), R$ is the gas constant $8.31 \times 10^{3}((\mathrm{~L} \cdot \mathrm{Pa}) /(\mathrm{K} \cdot \mathrm{mol}))$, $T$ is the temperature $(\mathrm{K}), P_{U}$ is the pressure of the gas in the high-pressure chamber $(\mathrm{Pa}), A$ is the area permeation of the gas through the sample $\left(\mathrm{m}^{2}\right)$, and $d p / d t$ is the change in pressure over time $(\mathrm{Pa} / \mathrm{s})$. The coefficient of gas permeability $(P)$ was then calculated as

$$
P=G T R \cdot d
$$

where $d$ is the thickness of the specimen (m). The morphology of the mineral fillers and composites was observed via scanning electron microscopy (SEM). Images were taken on a LEO 1530 Gemini scanning electron microscope (Zeiss/LEO, Oberkochen, Germany). Prior to the measurements, the vulcanizates were broken in liquid nitrogen. A cone calorimeter (Fire Testing Technology Ltd., East Grinstead, UK) was applied to evaluate the flammability of the EPM composites, according to the PN-ISO 5660 standard. Each squared specimen, of dimensions $100 \mathrm{~mm} \times 100 \mathrm{~mm} \times 2 \mathrm{~mm}$, was irradiated horizontally using a $35 \mathrm{~kW} / \mathrm{m}^{2}$ incident heat flux. Thermogravimetric analysis (TGA) was performed using a thermal analyzer (Jupiter STA 449F3, Netzsch Company, Selb, Germany) in a temperatures range of $25-700{ }^{\circ} \mathrm{C}$ with a heating rate of $10^{\circ} \mathrm{C} \mathrm{min}^{-1}$ in a nitrogen atmosphere.

\section{Results}

\subsection{Curing Measurements}

The primary aim of this research was to investigate the effect of mineral fillers, PT and VMT, on the curing kinetics of EPM rubber. The cure properties were studied at $160{ }^{\circ} \mathrm{C}$ for $30 \mathrm{~min}$ using a moving die rheometer (MDR). The results of rheometric tests showed that the addition of PT and VMT had a significant influence on the curing behavior of EPM composites. The kinetic parameters of the EPM composites are summarized in Table 2.

Table 2. Rheometric parameters and crosslink density values of EPM-filled compounds.

\begin{tabular}{cccccc}
\hline Compound & $\mathbf{M}_{\mathbf{m i n}}(\mathbf{d N m})$ & $\boldsymbol{\Delta} \mathbf{M}(\mathbf{d N m})$ & $\mathbf{t}_{\mathbf{0 2}}(\mathbf{m i n})$ & $\mathbf{t}_{\mathbf{9} \mathbf{0}}(\mathbf{m i n})$ & $\boldsymbol{v}_{\mathbf{e}}\left(\mathbf{m o l} / \mathbf{c m}^{\mathbf{3}}\right)$ \\
\hline EPM & 0.81 & 4.80 & 1.07 & 18.84 & 3.4 \\
EPM/5PT & 0.91 & 5.41 & 1.09 & 17.29 & 4.5 \\
EPM/10PT & 0.98 & 6.08 & 1.03 & 17.20 & 5.3 \\
EPM/20PT & 1.14 & 7.19 & 0.91 & 15.76 & 5.9 \\
EPM/20PT/AMIMTFSI & 0.96 & 5.37 & 0.83 & 14.16 & 5.0 \\
EPM/20PT/BMIMTFSI & 0.97 & 5.42 & 0.90 & 15.28 & 4.8 \\
EPM/5VMT & 0.87 & 4.83 & 1.16 & 14.76 & 3.5 \\
EPM/10VMT & 0.93 & 4.86 & 1.03 & 13.29 & 3.6 \\
EPM/20VMT & 0.99 & 4.45 & 1.06 & 12.76 & 2.8 \\
EPM/20VMT/AMIMTFSI & 0.96 & 5.90 & 1.01 & 11.57 & 4.3 \\
EPM/20VMT/BMIMTFSI & 0.96 & 5.62 & 1.02 & 11.58 & 4.9 \\
\hline
\end{tabular}

$\mathrm{M}_{\text {min }}$-minimum torque moment, $\Delta \mathrm{M}$-increment of torque, $\mathrm{t}_{02}$-scorch time, $\mathrm{t}_{90}$-optimum curing time, $v_{\mathrm{e}}$-crosslink density.

First, it can be noted that the application of the mineral fillers caused an increase in the minimum torque moment of the EPM mixtures. The minimum torque value was related to the viscosity of the composites. The enhanced $\mathrm{M}_{\text {min }}$ following the addition of filler could indicate a hydrodynamic effect in the rubber systems filled with the rigid filler particles [34]. Furthermore, because of the relative compatibility between the rubber molecular chains and the mineral, $\Delta \mathrm{M}$ increases with the increasing loading of PT. The increment of torque during vulcanization is an indirect measurement of the degree 
of elastomer crosslinking. Hence, it can be concluded that the incorporation of PT will result in the enhancement in the crosslink density of EPM/PT compounds. On the other hand, no significant changes in $\triangle \mathrm{M}$ were observed for the EPM/VMT blends. For both fillers, a slight reduction in optimum curing time and scorch time was observed, in comparison with the neat EPM. The early start of the crosslinking process, as indicated by the curing times, is evidence of the positive contribution made by the studied minerals to the curing process.

The crosslink density values (see Table 2) corresponded with the variation in torque differences. The crosslink density of the EPM compounds increased in proportion to the content of the mineral fillers, with the maximum reached at $20 \mathrm{phr}\left(5.9 \mathrm{~mol} / \mathrm{cm}^{3}\right)$ of PT loading. The only exception was vulcanizate filled with $20 \mathrm{phr}$ of VMT, which showed a lower crosslink density value in comparison to the reference sample. These results suggest that the application of PT or VMT as fillers in EPM rubber may also have substantial impact on their mechanical performance. The results from Table 2 further show that the application of ionic liquids contributed to a slight reduction in the optimum curing time and scorch time of the studied composites. This is in agreement with data in the literature [35], which suggests that ionic liquids may act as catalysts for interface reactions and thereby significantly affect rheometric parameters. In our study, the crosslink density values of the EPM/VMT compounds were found to increase by approximately $2 \mathrm{~mol} / \mathrm{cm}^{3}$. There was, however, no clear effect on the IL structure. Furthermore, the EPM/VMT mixtures exhibited an enhanced increment of torque following the incorporation of TFSI-based (bis(trifluoromethylsulfonyl)imide) imidazolium ILs, regardless of the cation type. The improvement in the kinetic parameters of the systems with ILs can be also explained by the more homogenous distribution of the additives in the polymer matrix, which led to better contact between the components of the vulcanization system.

\subsection{Mechanical Properties}

The mechanical properties (tensile strength and tear resistance) of the EPM-filled composites are presented in Figure 2. Perlite was found to have a low reinforcing effect, as the tensile strength of the EPM/PT systems increased slightly from 3.4 MPa for neat EPM to 4.5 MPa for the composite filled with $20 \mathrm{phr}$ of PT mineral. However, the tear resistance of the EPM/PT composites increased rapidly with increasing contents of PT in the sample. These improvements in the mechanical properties of EPM/PT materials can be explained by their enhanced crosslink density and the relatively uniform dispersion of the PT particles. In the case of EPM/VMT composites, the tensile strength values remained unchanged or slightly decreased in comparison with the reference sample. The opposite results were obtained by Tjong et al. [36], after incorporation of VMT into a polypropylene (PP) matrix. In their study, the modification of VMT with maleic anhydride probably improved its compatibility with the PP matrix. On the other hand, VMT had a very strong impact on the tear resistance of the EPM compounds, which increased considerably from $1.90 \mathrm{~N} / \mathrm{mm}$ up to $4.56 \mathrm{~N} / \mathrm{mm}$ for the EPM/20VMT sample. Composites with layered fillers have been also been reported to have high tear resistance in other previous works $[37,38]$. The various effects of the studied minerals on the mechanical performance of EPM composites can be explained by the differences in the morphological features of the fillers and their compatibility with the EPM matrix. Applying TFSI-based imidazolium salts did not cause marked alterations in their mechanical parameters. The tensile strengths of the samples containing ILs were slightly lower, which is most likely to be related to the plasticizing effect of the studied ILs [39] (Figure 3a). However, the applied ILs may have a positive effect on the tear resistance of the perlite-filled EPM composites. It can be observed that the tear resistance of the EPM/20PT composite increased in both cases following the application of AMIMTFSI and BMIMTFSI, by approximately $42 \%$ and $20 \%$, respectively (Figure $3 \mathrm{~b}$ ). 

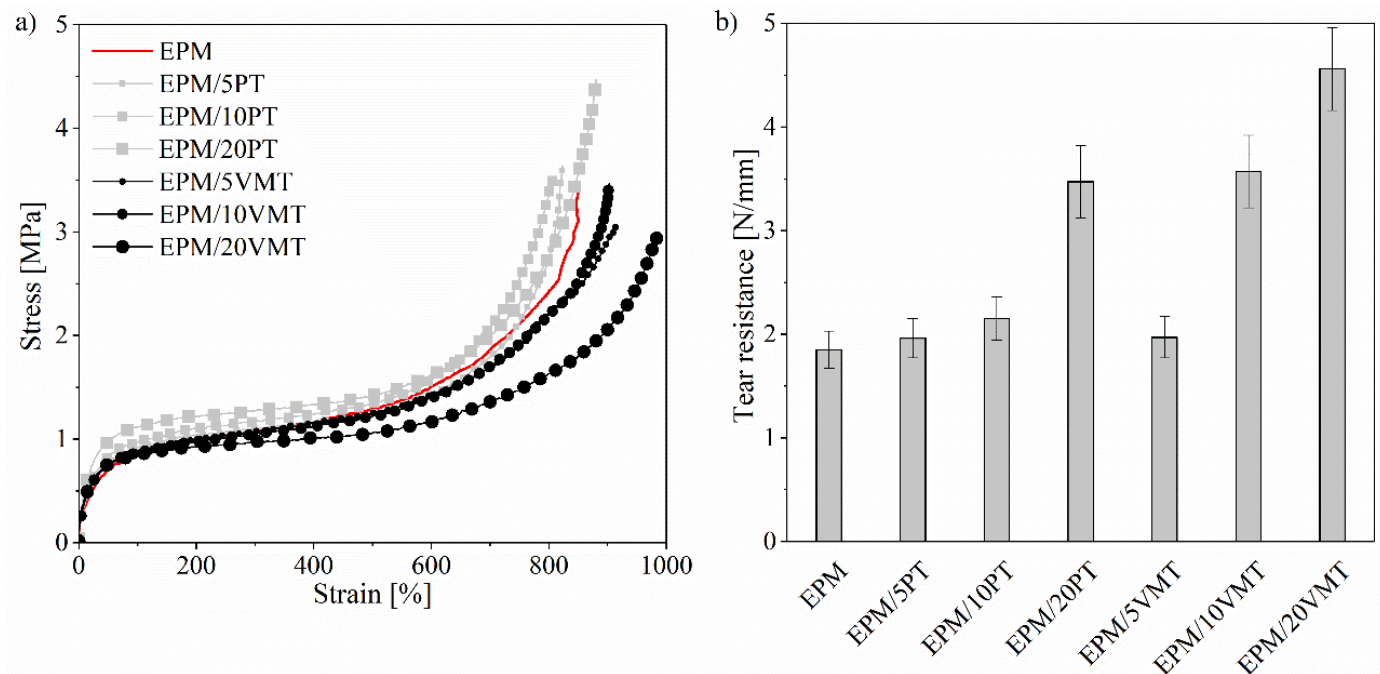

Figure 2. Mechanical curves of the studied EPM composites: (a) tensile test; (b) tear resistance.
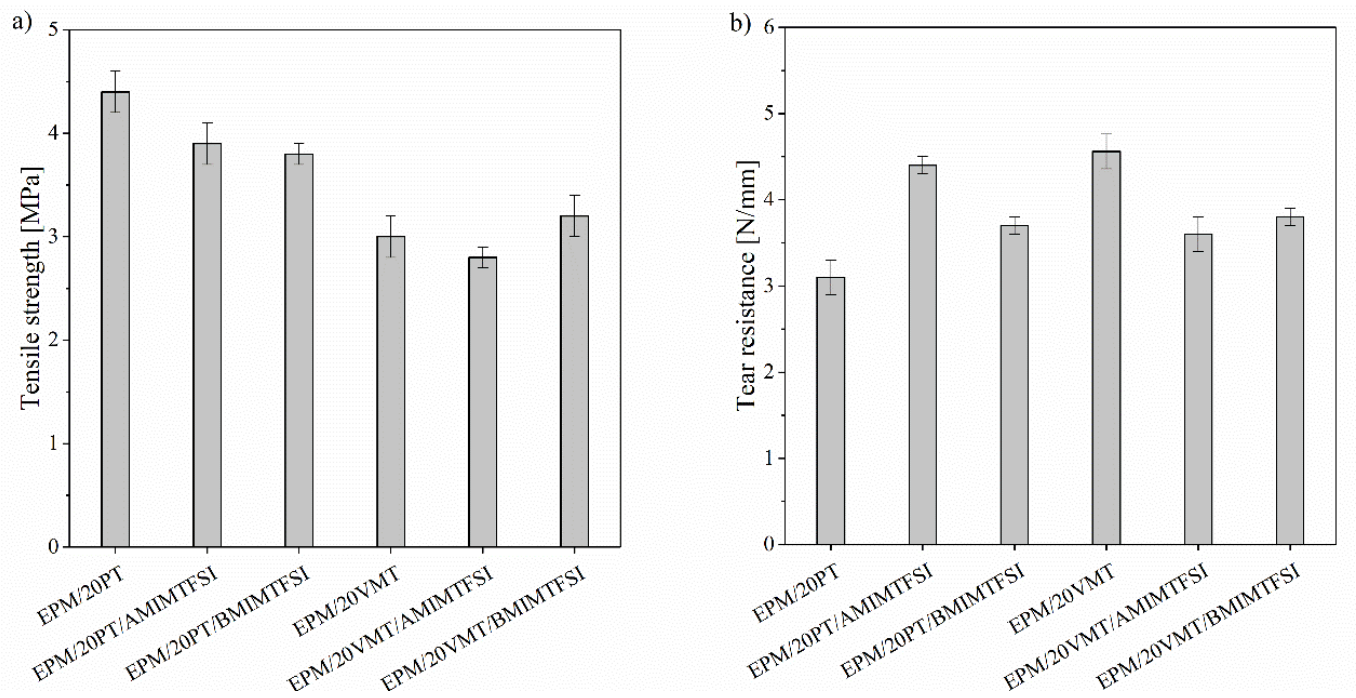

Figure 3. Mechanical parameters of the EPM composites with $20 \mathrm{phr}$ (parts per hundred parts of rubber) of filler and $2.5 \mathrm{phr}$ of ionic liquids: (a) tensile strength; (b) tear resistance.

\subsection{Barrier Performance}

The next objective of this study was to explore the gas permeation characteristics of EPM composites filled with PT and VMT. It is known from the literature $[40,41]$ that many different mineral fillers, such as montmorillonite or saponite, can be employed to improve the barrier performance of various polymeric materials. Therefore, EPM composites filled with increasing contents of PT and VMT were investigated in terms of their gas permeability, using the manometric method. The results are presented in Figure 4.

Figure 4 shows that the incorporation of VMT filler significantly improved the barrier performance of the EPM matrix. This is evidenced by the sharply reduced permeability coefficients of the EPM/VMT composites in relation to the reference. The barrier properties of the EPM systems improved with increasing concentrations of the VMT filler. The most visible improvement was observed for $20 \mathrm{phr}$ of VMT, when the gas permeability coefficient was reduced by approximately $12 \times 10^{8}((\mathrm{~mol} \cdot \mathrm{m}) /(\mathrm{m} \cdot \mathrm{s} \cdot \mathrm{Pa}))$ compared to neat EPM. This can be explained by the presence of an impermeable clay mineral layer formed by the plate-like VMT particles or by the restricted motion of rubber chains in the vicinity of the mineral filler particles [42]. Gas molecules must travel around individually deposited VMT platelets 
or stacks, which significantly extends the diffusion length traveled. Different results were observed for EPM composites containing perlite filler. In this case, the gas permeability coefficient values were similar to the reference, regardless of the filler concentration. The different geometric structures of the fillers (spherical for PT, lamellar for VMT) could have a decisive impact on the barrier properties of the EPM-filled composites. In addition, the effect of studied ILs on the barrier performance of the EPM composites were analyzed. The obtained results revealed that incorporation of $2.5 \mathrm{phr}$ of TFSI-based imidazolium ILs into EPM did not affect the air permeability of the investigated elastomer composites.

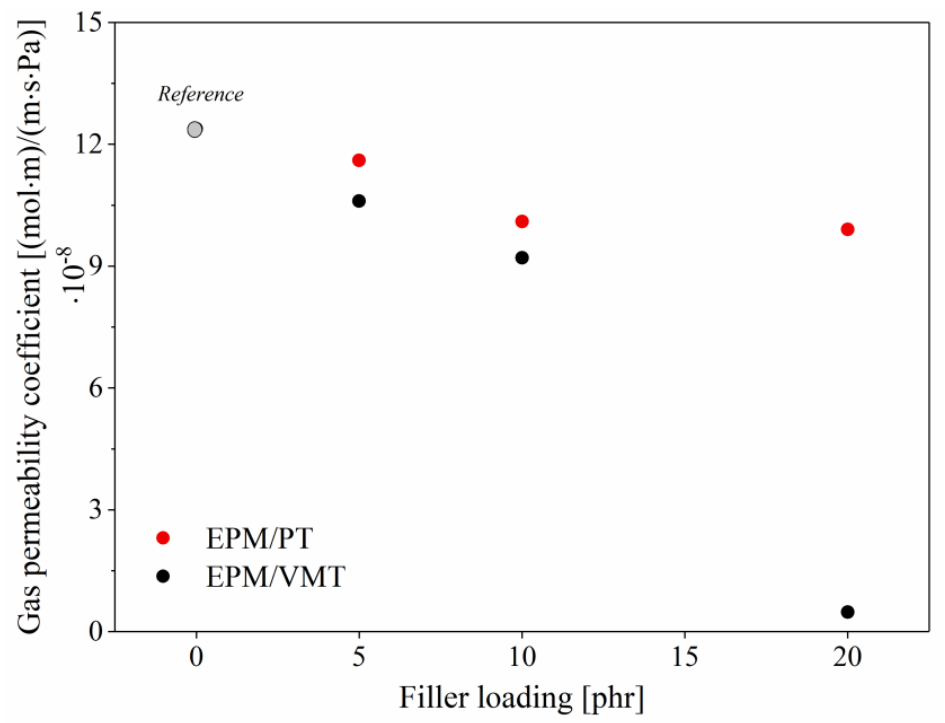

Figure 4. Gas permeability coefficient values for EPM composites filled with different contents of perlite and vermiculite.

\subsection{Thermal Stability}

The thermal stability of the studied mineral fillers as well as of the EPM composites was evaluated based on thermogravimetric analysis (TGA). The TGA curves and corresponding data are presented in Figures 5 and 6 and Table 3 .

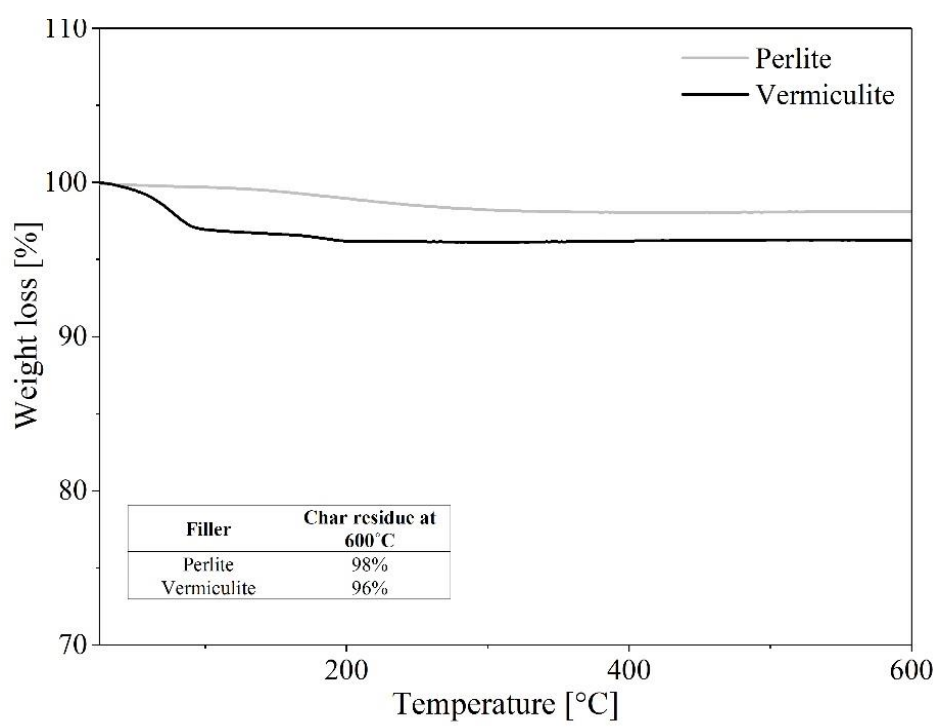

Figure 5. Thermogravimetric curves of the perlite and vermiculite minerals. 


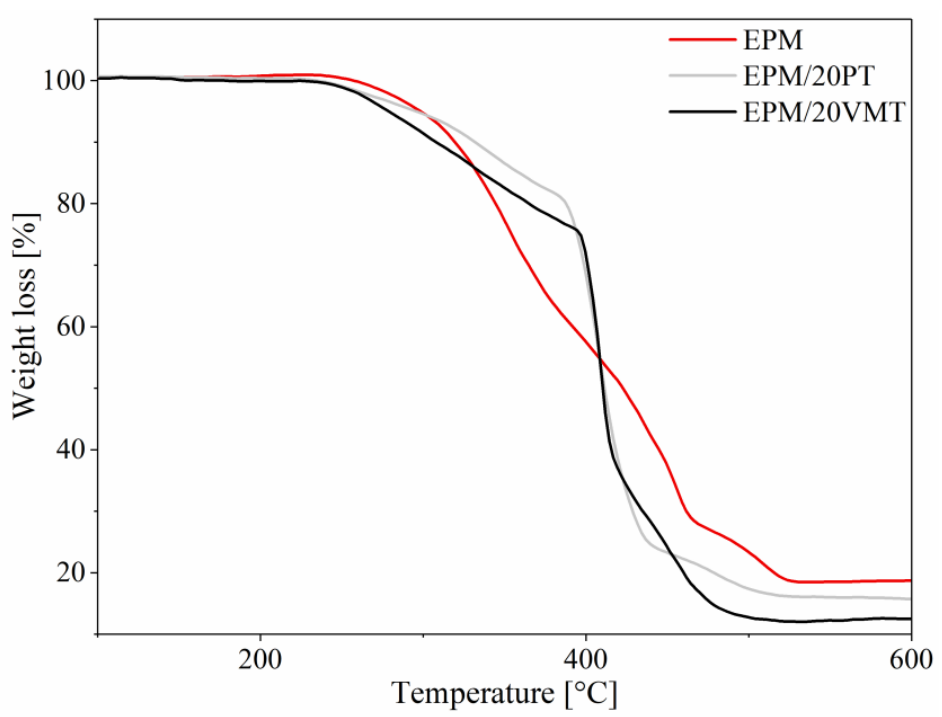

Figure 6. Thermogravimetric curves of the unfilled EPM elastomer and EPM composites with 20 phr of perlite and vermiculite fillers.

Table 3. Thermogravimetric data for EPM composites.

\begin{tabular}{|c|c|c|c|c|c|c|c|}
\hline Compound & $\begin{array}{c}\mathrm{T}_{5} \\
\left({ }^{\circ} \mathrm{C}\right)\end{array}$ & $\begin{array}{l}\mathrm{T}_{50} \\
\left({ }^{\circ} \mathrm{C}\right)\end{array}$ & $\begin{array}{c}T_{\text {RMAX1 } 1} \\
\left({ }^{\circ} \mathrm{C}\right)\end{array}$ & $\begin{array}{c}T_{\text {RMAX2 }} \\
\left({ }^{\circ} \mathrm{C}\right)\end{array}$ & $\begin{array}{c}\mathrm{dm} / \mathrm{dt}_{1} \\
(\% / \mathrm{min})\end{array}$ & $\begin{array}{c}\mathrm{dm} / \mathrm{dt}_{2} \\
(\% / \mathrm{min})\end{array}$ & $\begin{array}{l}P_{600} \\
(\%)\end{array}$ \\
\hline EPM & 298 & 423 & 350 & 442 & 4.85 & 5.36 & 18.82 \\
\hline $\mathrm{EPM} / 5 \mathrm{PT}$ & 271 & 400 & 300 & 403 & 1.95 & 23.53 & 1.17 \\
\hline EPM/10PT & 272 & 405 & 305 & 401 & 1.38 & 17.3 & 6.63 \\
\hline $\mathrm{EPM} / 20 \mathrm{PT}$ & 278 & 410 & 270 & 407 & 1.50 & 34.76 & 12.61 \\
\hline $\mathrm{EPM} / 5 \mathrm{VMT}$ & 288 & 405 & 292 & 398 & 1.33 & 30.34 & 10.42 \\
\hline EPM/10VMT & 262 & 404 & 260 & 402 & 1.24 & 39.71 & 4.18 \\
\hline EPM/20VMT & 296 & 410 & 261 & 403 & 0.93 & 20.16 & 15.65 \\
\hline
\end{tabular}

$\mathrm{T}_{5,50}$ - temperature of sample $5 \%$ and $50 \%$ mass loss, $\mathrm{T}_{\mathrm{RMAX}}$-temperature for maximum rate of thermal decomposition of tested vulcanizates, $\mathrm{P}_{600}$-residue after thermal decomposition of the composites.

As shown in Figure 5, the thermal stability of both studied fillers is very high. The char residues registered at $600{ }^{\circ} \mathrm{C}$ for perlite and vermiculite were $98 \%$ and $96 \%$, respectively. The TGA curve of the vermiculite filler revealed slight weight loss at a temperature of approximately $100{ }^{\circ} \mathrm{C}$, which is typical for this mineral [43] and corresponds to physisorbed water molecules. These results suggest that the studied minerals are resistant to increasing heat in the examined temperature range. Thus, it can be supposed that the incorporation of perlite and/or vermiculite mineral into EPM may affect the thermal properties of the resulting composites, by protecting the elastomer matrix against high temperatures.

From Figure 6, it can be seen that all the EPM composites are stable, up to approximately $250{ }^{\circ} \mathrm{C}$. The weight loss curves indicate that the thermal degradation of the EPM rubber compounds consisted of three loss steps. The first relatively slow mass loss occurred at temperatures between 200 and $400{ }^{\circ} \mathrm{C}$, the second step can be observed in the range of $400-470{ }^{\circ} \mathrm{C}$, the third step was found to be between $470-530^{\circ} \mathrm{C}$. It should be noted that at the beginning of the second step of thermal degradation, the weight of the EPM/20PT and EPM/20VMT samples were $80 \%$ and $74 \%$, respectively, while for neat EPM rubber the weight was as much as $55 \%$. The weight loss values determined for these samples suggest that the addition of both PT and VMT to the studied EPM composites clearly limits its rate of thermal decomposition in the temperature range of $\Delta \mathrm{T}=200-400{ }^{\circ} \mathrm{C}$. However, above $440{ }^{\circ} \mathrm{C}$ the thermal decomposition of both the EPM/20PT and EPM/20VMT samples occurs with much more intensity than in the case of unfilled EPM vulcanizate, which means that the studied minerals may negatively affect the efficiency of thermal crosslinking and cyclization. For this reason, the char residue $\left(\mathrm{P}_{600}\right)$ assumes a higher value for crosslinked EPM rubber in comparison with its filled composites. 


\subsection{Flammability (Cone Calorimetry)}

The cone calorimetry test (CCT) is well-known as an effective bench-scale tool for investigating the flammability of polymer composites. This technique provides data that correlate well with those obtained from full-scale experiments [44]. Therefore, CCT was employed to evaluate the PT and VMT minerals as potential flame retardants for use in EPM rubber composites. The CCT experiments were performed for EPM composites with increasing loading of the fillers. The results are presented in Table 4 and Figure 7.

Table 4. Flammability parameters of EPM composites.

\begin{tabular}{|c|c|c|c|c|c|c|c|}
\hline Compound & $\begin{array}{l}\text { TTI } \\
\text { (s) }\end{array}$ & $\begin{array}{c}\text { HRR } \\
\left(\mathrm{kW} / \mathrm{m}^{2}\right)\end{array}$ & $\begin{array}{l}H_{R R} \max \\
\left(k W / m^{2}\right)\end{array}$ & $\begin{array}{c}\text { THR } \\
\left(\mathrm{MJ} / \mathrm{m}^{2}\right)\end{array}$ & $\begin{array}{c}\text { EHC } \\
(\mathrm{MJ} / \mathrm{kg})\end{array}$ & $\begin{array}{l}\mathrm{EHC}_{\max } \\
(\mathrm{MJ} / \mathrm{kg})\end{array}$ & $\begin{array}{c}\text { MLR } \\
\left(\mathrm{g} / \mathrm{m}^{2} \cdot \mathrm{s}\right)\end{array}$ \\
\hline EPM & 70 & 202.7 & 576.0 & 92.9 & 51.0 & 79.0 & 0.206 \\
\hline $\mathrm{EPM} / 5 \mathrm{PT}$ & 68 & 204.1 & 445.9 & 57.7 & 31.8 & 77.5 & 0.257 \\
\hline $\mathrm{EPM} / 10 \mathrm{PT}$ & 70 & 195.5 & 390.5 & 49.8 & 38.1 & 79.2 & 0.212 \\
\hline $\mathrm{EPM} / 20 \mathrm{PT}$ & 90 & 66.34 & 189.7 & 16.6 & 10.4 & 64.2 & 0.224 \\
\hline EPM/20PT/AMIMTFSI & 120 & 61.23 & 179.3 & 17.0 & 8.9 & 62.1 & 0.200 \\
\hline EPM/20PT/BMIMTFSI & 110 & 63.52 & 170.2 & 16.2 & 9.3 & 60.2 & 0.265 \\
\hline $\mathrm{EPM} / 5 \mathrm{VMT}$ & 70 & 185.3 & 560.1 & 70.1 & 46.6 & 72.1 & 0.211 \\
\hline EPM/10VMT & 73 & 171.8 & 529.6 & 47.9 & 75.8 & 78.2 & 0.014 \\
\hline $\mathrm{EPM} / 20 \mathrm{VMT}$ & 80 & 177.3 & 435.8 & 53.9 & 29.8 & 77.2 & 0.023 \\
\hline EPM/20VMT/AMIMTFSI & 105 & 145.7 & 401.6 & 51.5 & 26.9 & 74.2 & 0.245 \\
\hline EPM/20VMT/BMIMTFSI & 75 & 120.5 & 380.5 & 49.7 & 21.3 & 69.5 & 0.213 \\
\hline
\end{tabular}

TTI-time to ignition; HRR - heat release rate; $H_{R R} \max$ - $\max$ heat release rate; THR—-total heat release; $\mathrm{EHC}$ - effective heat of combustion; $\mathrm{EHC}_{\max }$-max effective heat of combustion; MLR—mass loss rate.

a)

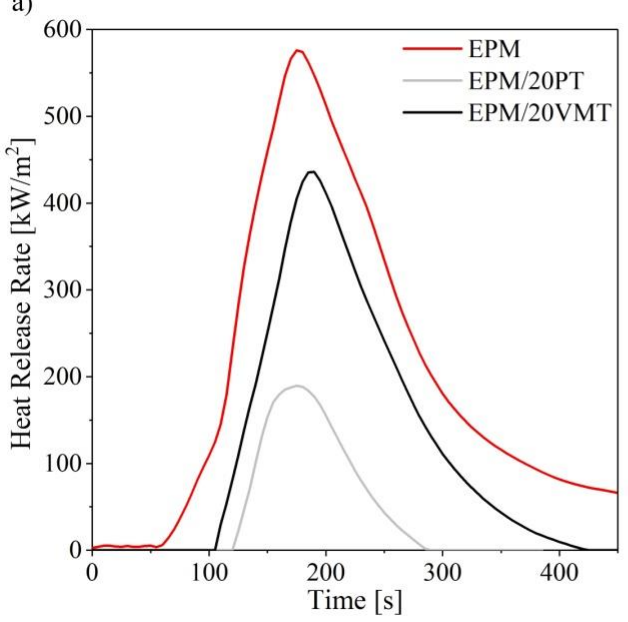

b)

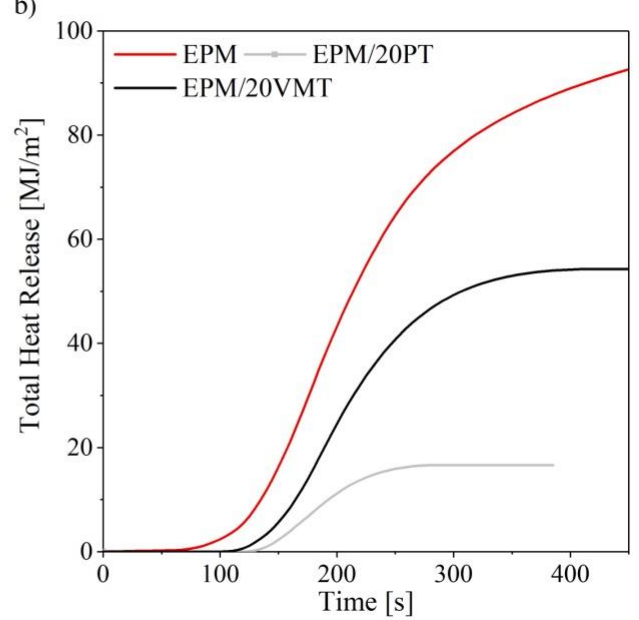

Figure 7. Cone calorimetry test results showing flammability parameters of the EPM composites:

(a) HRR vs. time and, (b) THR vs. time curves.

From the CCT data, it is clear that the flammability parameters were significantly reduced by the incorporation of the studied minerals into the polymer matrix. For instance, in the case of EPM/20PT, the $\mathrm{HRR}_{\max }$ parameter was reduced by $67 \%$ and the THR parameter by $76 \%$ with respect to the reference sample, while in the case of EPM/20VMT they fell by $25 \%$ and $42 \%$, respectively. Furthermore, the effective heat of combustion (EHC) parameter also decreased significantly with increasing loading of the fillers, suggesting lower flammability. This decrease in EHC may also be connected with the release of physisorbed water from the minerals during thermal decomposition, as the EHC parameter measured in the CCT experiment corresponds closely to the flame burning condition and thus to the combustion of volatiles from the material [45]. Importantly, the EPM-filled composites containing TFSI-based imidazolium ILs exhibited the sharpest reduction in terms of flammability. This means 
that the studied thermally-stable ionic liquids improved the flame retardancy of the EPM/PT and EPM/VMT systems.

It has been previously reported that TFSI-based ionic liquid may affect the thermal stability of some rubber composites [46]. Generally, the improvement in the flame retardancy of the EPM composites filled with PT and/or VMT minerals may be explained by the fact that the minerals inhibit the degradation rate of EPM rubber in the initial stage of the thermal degradation process. Moreover, due to the very the high thermal insulation and fire resistance of these minerals they may hinder heat transfer within the composite matrix. On the other hand, after the burning process, the filler particles may form so-called filler islets in the polymer matrix, which do not provide sufficient protection against external heat sources. The fillers cannot therefore be said to have a positive effect on the structure and/or insulating properties of the boundary layer. However, PT and VMT minerals can be considered as inexpensive and natural flame-retardant agents for elastomer composites, which are, above all, effective at relatively low concentrations, as evidenced by the considerably reduced HRR, HRR $\max$, THR, and EHC parameters (Table 4).

\subsection{Morphology}

Figure 8a-d shows SEM micrographs of the filler particles and EPM composites containing $10 \mathrm{phr}$ of each filler. Figure 8 a depicts the microstructure of the PT raw granules, characterized by fragmented surfaces with irregular small shreds and a highly porous microstructure containing mainly open pores. The VMT granules have different sizes, in the range of a several microns, with a platelet structure. Figure $8 \mathrm{c}, \mathrm{d}$ shows cross-sections of the EPM/PT and EPM/VMT composites. It appears that both composites consist of a mixture of individual platelets of VMT or PT and some stacks of platelets.

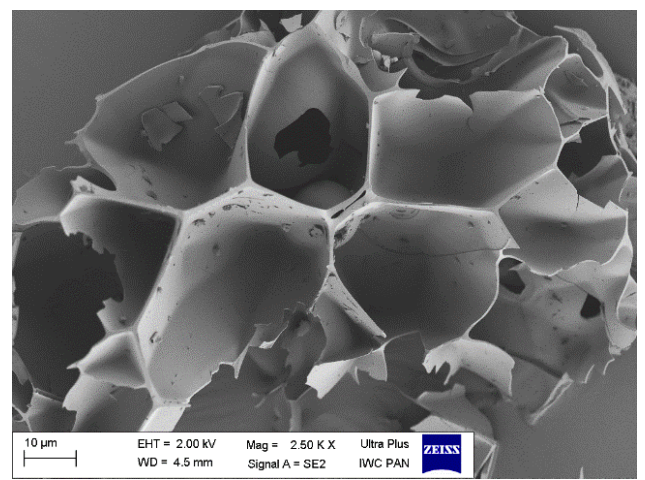

(a)

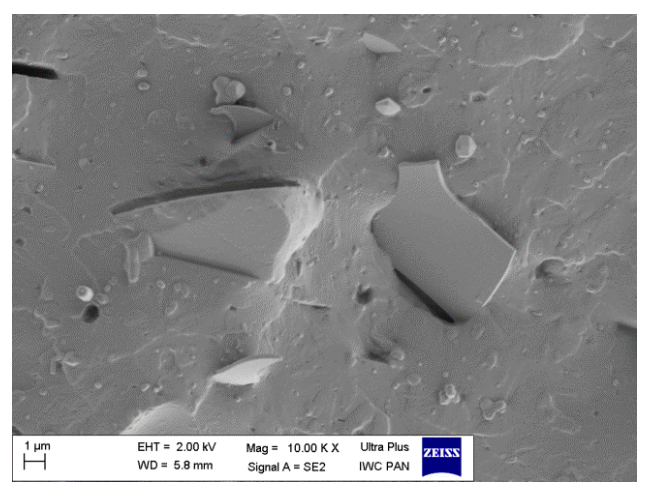

(c)

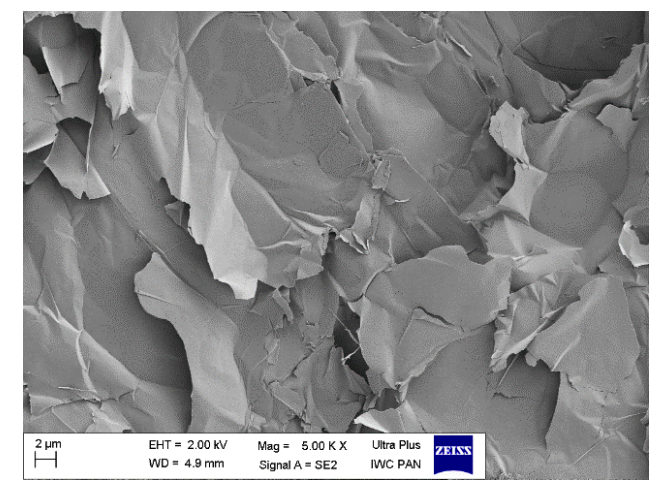

(b)

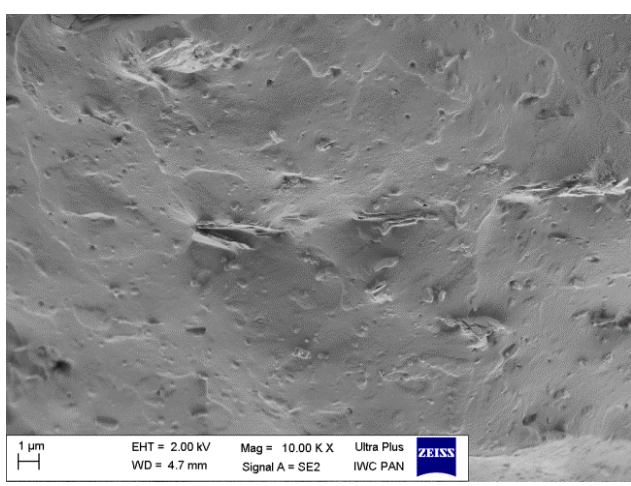

(d)

Figure 8. SEM microphotographs of: (a) perlite; (b) vermiculite; (c) EPM composite filled with 10 phr of perlite; (d) EPM composite filled with $10 \mathrm{phr}$ of vermiculite. 


\section{Conclusions}

This study investigated the effects of two natural minerals, perlite (PT) and vermiculite (VMT), on the properties of ethylene-propylene rubber composites. Three different concentrations of the fillers were used (5, 10 and $20 \mathrm{phr})$. TFSI-based imidazolium ionic liquids were added to improve filler-polymer compatibility. Comprehensive tests revealed that the studied minerals had a considerable effect on the curing and mechanical properties of the EPM elastomer. The application of PT contributed to improve the torque moment, crosslink density, and tensile strength of the compounds. On the other hand, VMT had a more pronounced impact on the tear resistance and barrier performance of the EPM systems. The varied effects of the studied fillers on the mechanical and barrier properties of the EPM compounds probably resulted from their different structures. It was found that ionic liquids had a catalytic effect on the crosslinking process. Importantly, TGA and CCT analyses revealed that the studied minerals and ionic liquids had a strong effect on the thermal and flame-retardant properties of the EPM compounds, especially in the case of EPM/PT systems. This can be explained by the inhibited rate of degradation in the initial stage and the very high thermal insulation properties of the studied minerals. Therefore, both PT and VMT can be considered for use in the preparation of novel and inexpensive elastomeric materials with improved flame retardancy and gas barrier stability, suitable for important and practical applications in rubber technology.

Author Contributions: Conceptualization, methodology, formal analysis, investigation, data curation, writing original draft, B.S. and A.M.; investigation and writing original draft P.R.; investigation and writing original draft W.Ż.; supervision, M.Z. All authors have read and agreed to the published version of the manuscript.

Funding: This research received no external funding.

Conflicts of Interest: The authors declare no conflict of interest.

\section{References}

1. Hirano, K.; Asami, M. Phenolic resins-100 years of progress and their future. React. Funct. Polym. 2013, 73, 256-269. [CrossRef]

2. Cheong, J.Y.; Ahn, J.; Seo, M.; Nam, Y.S. Flame-retardant, flexible vermiculite-polymer hybrid film. RSC Adv. 2015, 5, 61768-61774. [CrossRef]

3. Wang, X.; Song, L.; Yang, H.; Lu, H.; Hu, Y. Synergistic effect of graphene on antidripping and fire resistance of intumescent FR poly (butylene succinate) composites. Ind. Eng. Chem. Res. 2011, 50, 5376-5383. [CrossRef]

4. Wu, Z.; Wang, H.; Tian, X.; Ding, X.; Xue, M.; Zhou, H.; Zheng, K. Mechanical and flame-retardant properties of styrene-ethylene-butylene-styrene/carbon nanotube composites containing bisphenol A bis (diphenyl phosphate). Compos. Sci. Technol. 2013, 82, 8-14. [CrossRef]

5. Janas, D.; Rdest, M.; Koziol, K. Flame-retardant carbon nanotube films. Appl. Surf. Sci. 2017, 411, 177-181. [CrossRef]

6. Becker, C.M.; Gabbardo, A.D.; Wypych, F.; Amico, S.C. Mechanical and flame retardant properties of epoxy/Mg-Al based LDH composites. Compos. Part A 2011, 42, 196-202. [CrossRef]

7. Olfs, H.W.; Torres-Dorante, L.O.; Eckelt, R.; Kosslick, H. Comparison of different synthesis routes for Mg-Al layered double hydroxides (LDH): Characterization of the structural phases and anion exchange properties. Appl. Clay Sci. 2009, 43, 459-464. [CrossRef]

8. Tang, Y.; Hu, Y.; Wang, S.; Gui, Z.; Chen, Z.; Fan, W. Intumescent flame retardant-montmorillonite synergism in polypropylene-layered silicate nanocomposites. Polym. Int. 2003, 52, 1396-1400. [CrossRef]

9. Haurie, L.; Fernandez, A.I.; Velasco, J.I.; Chimenos, J.M.; Lopez Cuesta, J.-M.; Espiell, F. Thermal stability and flame retardancy of LDPE/EVA blends filled with synthetic hydromagnesite/aluminium hydroxide/montmorillonite and magnesium hydroxide/aluminium hydroxide/montmorillonite mixtures. Polym. Degrad. Stab. 2007, 92, 1082-1087. [CrossRef]

10. Kader, M.A.; Kim, K.; Lee, Y.-S.; Nah, C. Preparation and properties of nitrile rubber/montmorillonite nanocomposites via latex blending. J. Mater. Sci. 2006, 41, 7341-7352. [CrossRef]

11. Khobragade, P.S.; Hansora, D.P.; Naik, J.B.; Chatterjee, A. Flame retarding performance of elastomeric nanocomposites: A review. Polym. Degrad. Stab. 2016, 130, 192-244. [CrossRef] 
12. Talway, K.E. Chitosan phosphate: A new way for production of eco-friendly flame-retardant cotton textiles. J. Text. Inst. 2008, 99, 185-191.

13. Jana, T.; Roy, B.C.; Maiti, S. Biodegradable film: 7. Modification of the biodegradable film for fire retardancy. Polym. Degrad. Stab. 2000, 69, 79-82. [CrossRef]

14. Mishra, S.; Sonawane, S.H.; Singh, R.P.; Bendale, A.; Patil, K. Effect of nano- $\mathrm{Mg}(\mathrm{OH})_{2}$ on the mechanical and flame-retarding properties of polypropylene composites. J. Appl. Polym. Sci. 2004, 94, 116-122. [CrossRef]

15. Ren, Q.; Zhang, Y.; Li, J.; Li, J.C. Synergistic effect of vermiculite on the intumescent flame retardance of polypropylene. J. Appl. Polym. Sci. 2010, 120, 1225-1233. [CrossRef]

16. Wang, F.; Gao, Z.; Zheng, M.; Sun, J. Thermal degradation and fire performance of plywood treated with expanded vermiculite. Fire Mater. 2016, 40, 427-433. [CrossRef]

17. Park, Y.; Qian, Y.; Lindsay, C.; Nijs, C.; Camargo, R.; Stein, A.; Macosko, C. Polyol-assisted vermiculite dispersion in polyurethane nanocomposites. ACS Appl. Mater. Interfaces 2013, 5, 3054-3062. [CrossRef]

18. Machado, L.C.R.; Lima, F.W.J.; Paniago, R.; Ardisson, J.D.; Sapag, K.; Lago, R.M. Polymer coated vermiculite-iron composites: Novel floatable magnetic adsorbents for water spilled contaminants. Appl. Clay Sci. 2006, 31, 207-215. [CrossRef]

19. Suvorov, S.A.; Skurikhin, V.V. Vermiculite-A promising material for high-temperature heat insulators. Refract. Ind. Ceram. 2003, 44, 186-193. [CrossRef]

20. Takahashi, S.; Goldberg, H.A.; Feeney, C.A.; Karim, D.P.; Farrell, M.; O’Leary, K.; Paul, D.R. Gas barrier properties of butyl rubber/vermiculite nanocomposite coatings. Polymer 2006, 47, 3083-3093. [CrossRef]

21. Tjong, S.C.; Meng, Y.Z. Impact-modified polypropylene/vermiculite nanocomposites. J. Polym. Sci. Polym. Phys. 2003, 41, 2332-2341. [CrossRef]

22. Chen, S.; Wang, B.; Kang, J.; Chen, J.; Gai, J.; Yang, L.; Cao, Y. Synergistic effect of organic vermiculite on the flame retardancy and thermal stability of intumescent polypropylene composites. J. Macromol. Sci. Part B Phys. 2014, 52, 1212-1225. [CrossRef]

23. Qian, Y.; Lindsay, C.; Macosko, C.; Stein, A. Synthesis and Properties of Vermiculite-Reinforced Polyurethane Nanocomposites. ACS Appl. Mater. Interfaces 2011, 3, 3709-3717. [CrossRef] [PubMed]

24. Papa, E.; Medri, V.; Murri, A.N.; Laghi, L.; De Aloysio, G.; Bandini, S.; Landi, E. Characterization of alkali bonded expanded perlite. Constr. Build. Mater. 2018, 191, 1139-1147. [CrossRef]

25. Celik, A.G.; Kilic, A.M.; Cakal, G.O. Expanded perlite aggregate characterization for use as a lightweight construction raw material. Physicochem. Probl. Miner. Process. 2013, 49, 689-700.

26. Sahraeian, R.; Hashemi, S.A.; Esfandeh, M.; Ghasemi, I. Preparation of nanocomposites based on LDPE/Perlite: Mechanical and Morphological Studies. Polym. Polym. Compos. 2012, 20, 639-645. [CrossRef]

27. Sahraeian, R.; Esfandeh, M.; Hashemi, S.A. Rheological, thermal and dynamic mechanic studies of LDPE/Perlite nanocomposites. Polym. Polym. Compos. 2013, 21, 243-249.

28. Karaca, E.; Omeroglu, S.; Akcam, O. Investigation of the effects of perlite additive on some comfort and acoustical properties of polyester fabrics. J. Appl. Polym. Sci. 2016, 133, 43128. [CrossRef]

29. Marzec, A.; Laskowska, A.; Boiteux, G.; Zaborski, M.; Gain, O.; Serghei, A. Study on weather aging of nitrile rubber composites containing imidazolium ionic liquids. Macromol. Symp. 2014, 342, 25-34. [CrossRef]

30. Laskowska, A.; Marzec, A.; Boiteux, G.; Zaborski, M.; Gain, O.; Serghei, A. Investigations of nitrile rubber composites containing imidazolium ionic liquids. Macromol. Symp. 2014, 341, 18-25. [CrossRef]

31. Marzec, A.; Laskowska, A.; Boiteux, G.; Zaborski, M.; Gain, O.; Serghei, A. Properties of carboxylated nitrile rubber/hydrotalcite composites containing imidazolium ionic liquids. Macromol. Symp. 2014, 341, 7-17. [CrossRef]

32. Flory, P.J. Statistical mechanics of swelling of network structures. J. Chem. Phys. 1950, 18, 108-111. [CrossRef]

33. Szadkowski, B.; Marzec, A.; Rybiński, P.; Maniukiewicz, W.; Zaborski, M. Aluminum-magnesium hydroxycarbonate/azo dye hybrids as novel multifunctional colorants for elastomer composites. Polymers 2019, 11, 43. [CrossRef]

34. Bokobza, L.; Rapoport, O. Reinforcement of natural rubber. J. Appl. Polym. Sci. 2002, 85, 2301-2316. [CrossRef]

35. Pingot, M.; Szadkowski, B.; Zaborski, M. Experimental investigation on activity of cumene hydroperoxide and selected ionic liquids in butadiene rubber vulcanization. Adv. Polym. Technol. 2018, 37, 3432-3437. [CrossRef] 
36. Tjong, S.C.; Meng, Y.Z.; Hay, A.S. Novel preparation and properties of polypropylene-vermiculite Nanocomposites. Chem. Mater. 2002, 14, 44-51. [CrossRef]

37. Laskowska, A.; Zaborski, M.; Boiteux, G.; Gain, O.; Marzec, A.; Maniukiewicz, W. Ionic elastomers based on carboxylated nitrile rubber (XNBR) and magnesium aluminum layered double hydroxide (hydrotalcite). Express Polym. Lett. 2014, 8, 374-386. [CrossRef]

38. Gatos, K.; Karger-Kocsis, J. Effect of the aspect ratio of silicate platelets on the mechanical and barrier properties of hydrogenated acrylonitrile butadiene rubber (HNBR)/layered silicate nanocomposites. Eur. Polym. J. 2007, 43, 1097-1104. [CrossRef]

39. Subramaniam, K.; Das, A.; Heinrich, G. Development of conducting poly-chloroprene rubber using imidazolium based ionic liquid modified multi-walled carbon nanotubes. Compos. Sci. Technol. 2011, 71, 1441-1449. [CrossRef]

40. Kalendova, A.; Merinska, D.; Gerard, J.F.; Slouf, M. Polymer/clay nanocomposites and their gas barrier properties. Polym. Compos. 2013, 34, 1418-1424. [CrossRef]

41. Yano, K.; Usuki, A.; Okada, A.; Kurauchi, T.; Kamigaito, O. Synthesis and properties of polyimide-clay hybrid. J. Polym. Sci. Polym. Chem. 1993, 31, 2493-2498. [CrossRef]

42. Zhang, Y.; Liu, Q.; Zhang, Q.; Lu, Y. Gas barrier properties of natural rubber/kaolin composites prepared by melt blending. Appl. Clay Sci. 2010, 50, 255-259. [CrossRef]

43. Folorunso, O.; Dodds, C.; Dimitrakis, G.; Kingman, S. Continuous energy efficient exfoliation of vermiculite through microwave heating. Int. J. Miner. Process. 2012, 114-117, 69-79. [CrossRef]

44. Babrauskas, V.; Grayson, J.S. Heat Release in Fires; Elsevier Applied Science: London, UK, 1992; pp. 61-173.

45. Grexa, O.; Lübke, H. Flammability parameters of wood tested on a cone calorimeter. Polym. Degrad. Stab. 2001, 74, 427-432. [CrossRef]

46. Subramaniam, K.; Das, A.; Steinhauser, D.; Klüppel, M.; Heinrich, G. Effect of ionic liquid on dielectric, mechanical and dynamic mechanical properties of multi-walled carbon nanotubes/polychloroprene rubber composites. Eur. Polym. J. 2011, 47, 2234-2243. [CrossRef]

(C) 2020 by the authors. Licensee MDPI, Basel, Switzerland. This article is an open access article distributed under the terms and conditions of the Creative Commons Attribution (CC BY) license (http://creativecommons.org/licenses/by/4.0/). 